Digilec 5 (2018), pp. 105-112

Fecha de recepción: 01/11/2018

Fecha de aceptación: 05/11/2018

DOI: https://doi.org/10.17979/digilec.2018.5.0.4984

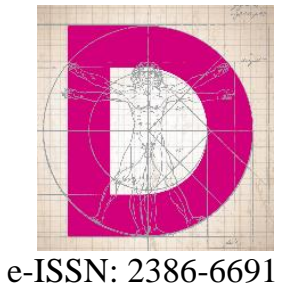

\title{
ISABEL ZENDAL E OS NENOS DA VARÍOLA. OBRA DE TEATRO INFANTIL
}

\author{
ISABEL ZENDAL E OS NENOS DA VARÍOLA. CHILDREN'S PLAY
}

\author{
Sinda CUNDINS CAAMAÑO* \\ CEIP Labarta Pose (Baio, Zas, A Coruña)
}

\begin{abstract}
Resumo
Neste traballo preséntase unha obra de teatro infantil adaptada pola profesora Sinda Cundins Caamaño do CEIP Labarta Pose de Baio (Concello de Zas, A Coruña). Está inspirada na novela de María Solar Os nenos da varíola (2017) e nas investigacións de Antonio López Mariño sobre o papel de Isabel Zendal, Reitora do Hospicio da Coruña, e unha das protagonistas da expedición da varíola que parte a América desde Coruña a principios do século XIX. Ademais do texto, inclúese na presente achega unha representación da obra a cargo dos nenos e nenas de $6^{\circ}$ de Primaria do CEIP Labarta Pose, do curso 2017/2018, baixo a dirección da súa profesora, autora do presente traballo. A representación realizouse o 18 de abril de 2018 no Reitorado da Universidade da Coruña no marco dun Proxecto de Aprendizaxe Servizo (ApS) realizado polos profesores Begoña Bas e Roberto García Morís, co seu alumnado de $3^{\circ}$ do Grao de Educación Primaria da Universidade da Coruña e o alumnado de $2^{\circ}$ de ESO do IES Ramón Menéndez PidalZalaeta, dentro dun Proxecto de Educación para o Desenvolvemento dirixido pola ONG Arquitectura sen Fronteiras (ASF).
\end{abstract}

Palabras clave: Obra de teatro; Os nenos da varíola; Expedición Balmis; teatro infantil.

\section{Abstract}

This work presents an children's play adapted by Sinda Cundins Caamaño from the Primary School Labarta Pose de Baio (Zas, A Coruña). María Solar Os nenos da varíola (2017) is inspired by Antonio López Mariño's research on the role of Isabel Zendal, headmaster of an orphanage in a Coruña, and several protagonists of the chickenpox expedition that travelled to America from Coruña at the beginning the XIX century. There is also a performance of the work in charge of two children in the 6th grade of Primary School Labarta Pose, directed by their teacher and author of the current work. The performace took place on April $18^{\text {th }}, 2018 \mathrm{n}$ at the main auditorium at UDC within the framework of the Service-Learning Project in charge of the UDC professors Begoña Bas and Roberto García Morís, in collaboration with their $3^{\text {rd }}$ Year Degree in Primary Education students and with the $4^{\text {th }}$ year of Secondary Education students from the Secondary School Ramón Menéndez Pidal-Zalaeta, and within a Project for Education for Development, directed by NGO Architecture without fronteers (ASF).

Key Words: Drama; Os nenos da varíola; Balmis Expedition; children's theater. 
Isabel Zendal e os nenos da varíola

Este guión é unha adaptación da novela Os nenos da varíola de María Solar (Editorial Galaxia, 2017).

Na seguinte ligazón pódese ver a representación da obra de teatro o 18 de abril de 2018 no paraninfo da Universidade da Coruña. Gravada e editada por Arquitectura sen Fronteiras (ASF-Galicia), a través da súa canle de difusión de youtube.

Representación da obra de teatro Isabel Zendal e os nenos da varíola

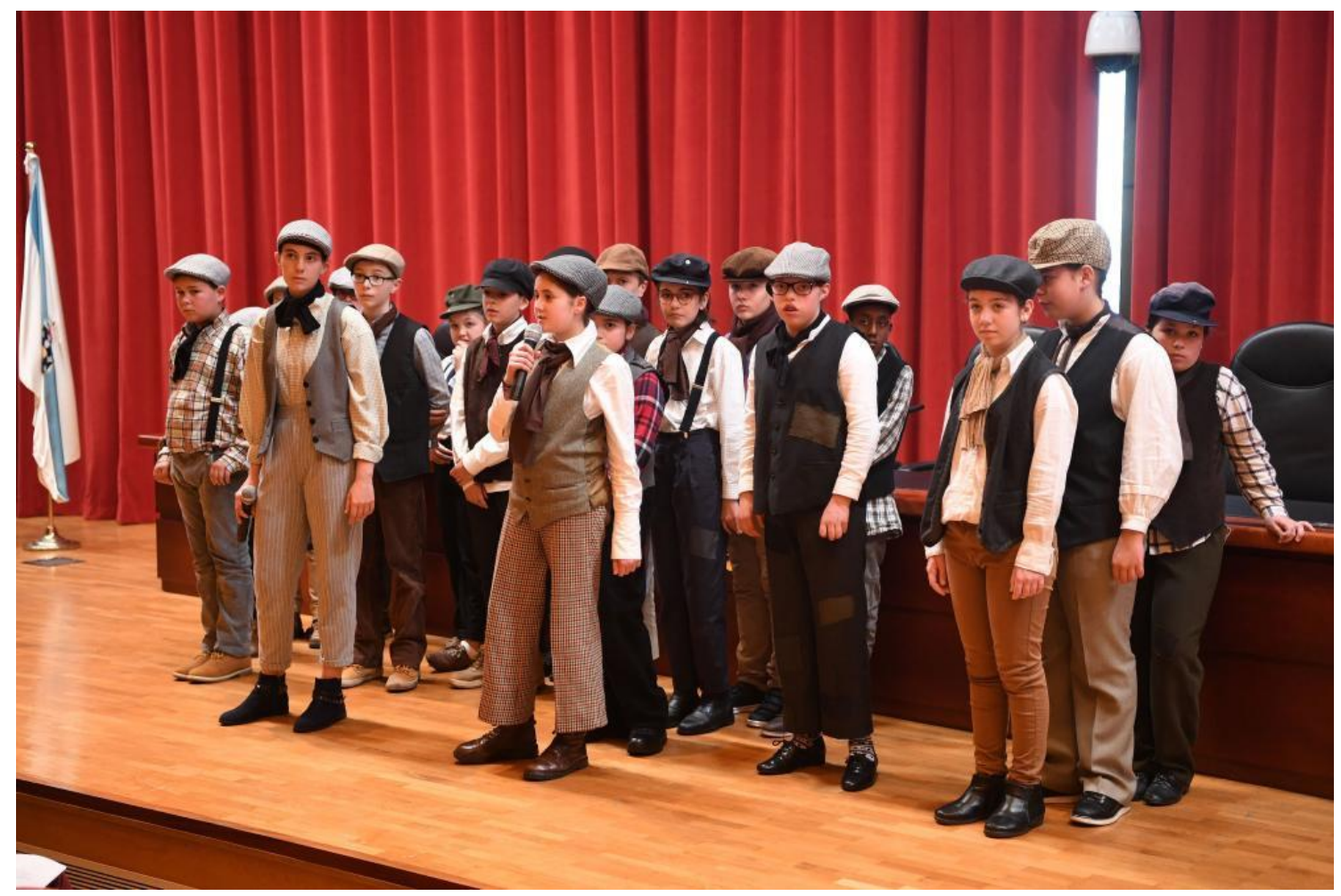

Imaxe de Víctor Echave, La Opinión A Coruña

Entran os nenos e nenas, caracterizados de época, e van ocupando o escenario mentres soa a música.

\section{POSSE ROYBANES}

- Son o médico Posse Roybanes, colaborador de Balmis nos procesos de vacinación para manter activo o virus da varíola. O 30 de novembro de 1803 partía do porto da Coruña a corveta María Pita. Comezaba a travesía da Real Expedición Filantrópica da Vacina, dirixida por Francisco Xabier Balmis e financiada por Carlos IV. Esta xesta demostrou ao mundo, hai xa 200 anos, que a inmunización perfecta contra as enfermidades contaxiosas é infectarse, estando san, co mesmo mal que se quere evitar.

A vacina viaxaba, viva e activa, mediante inoculacións de brazo a brazo, que posibilitaban os nenos recrutados para a Expedición. A viaxe foi moi dura. O barco era 
un feixe de perigos continuos. Houbo accidentes, feridos, enfermidades e mareos. Os grandes heroes da expedición foron os expósitos, con idades entre os 2 e os 9 anos, que garantiron a cadea de transmisión da vacina.

Coidar dos rapaces que levaron a vacina da varíola desde A Coruña ata México foi responsabilidade directa da que foi considerada como A Primeira Enfermeira da Sanidade Pública: Isabel Zendal!

Música: "Prólogo”.

\section{SALVANY}

- Son Josep Salvany, axudante primeiro do doutor Balmis. As poboacións indíxenas de América están tan resentidas polas varíolas que morren por milleiros. Algunhas vilas indíxenas desapareceron do mapa. Os nativos morren en moitos máis número que os europeos. O rei recibiu as súplicas dos gobernadores de ultramar. Están vivindo a máis grande epidemia coñecida.

O doutor Balmis é un dos gran defensores da vacina da varíola. É perfectamente consciente de que esta Expedición é unha auténtica odisea que, de saír ben, nos situará nos libros de historia polos séculos dos séculos. É unha fazaña de tal dimensión que só un home ambicioso, intelixente e de forte personalidade como Balmis pode desenvolvela. Controlará todo en persoa evitando calquera improvisación.

A varíola será a enfermidade que máis persoas mate ao longo da historia da humanidade. Os nenos expósitos conseguirán cambiar o rumbo do mundo da man da valente enfermeira Isabel Zendal!

Música: "Outro día se vai", adaptado do musical Os Miserables.

Os nenos e nenas cantan e fan que dialogan entre eles.

\section{BALMIS}

- Son o doutor Francisco Xabier Balmis, director da Real Expedición Filantrópica da vacina. Imos implantar a vacina en toda América, nos territorios afíns e nos territorios hostís aos que poidamos chegar coa axuda dos mandos locais. Difundiremos a vacina e instruiremos os médicos na técnica da vacinación. Deste xeito, tras nós abandonar a zona, o método quedará asentado. Se non conseguimos difundir a vacina por todas partes fracasaremos, pero se o conseguimos será o maior logro sanitario acadado nunca pola humanidade.

Levaremos a vacina en vivo nunha cadea brazo a brazo, con nenos expósitos de idades comprendidas entre os 2 e os 9 anos. Todos serán rigorosamente escollidos para asegurarnos de que nunca estiveran en contacto coa varíola, ou a vacina non prendería neles. Vacinaremos aos rapaces de dous en dous, por asegurarnos de que, polo menos, prenda nun. Aos 9 ou 10 días, das pústulas dos enfermos, rasparemos un pouquiño de linfa para meterlla nunca incisión superficial no brazo doutro neno san. E así ímola transmitindo. A nosa intención é ter sempre vacina dispoñible en dous nenos. É 
fundamental que lles busquemos hospedaxes separadas e non contacten os vacinados co resto deles.

Só hai unha persoa que pode coidar como é debido deses cativos. Unha muller infatigable e intelixente: Isabel Zendal!

Música: "Son do ar".

\section{NENO 1}

- Son Andrés Naya, teño 8 anos e veño de Madrid. O doutor Edward Jenner extraeu un pouco de linfa das pústulas dunha muller infectada dunha vaca e inoculoulla a un neno san. Meses despois atacou ese rapaz con linfa procedente de pústulas de varíola humana e o rapaz non enfermou. Así demostrou que o pus vacún era a vacina perfecta.

\section{NENO 2}

- Eu son Domingo Naya, teño 6 anos e veño da casa dos Desamparados de Madrid. Os doutores din que nos van vacinar de dous en dous por se a vacina non prendera nalgún de nós.

\section{NENO 3}

- Son Vicente Ferrer, teño 7 anos e tamén veño do hospicio de Madrid. Vexo que non nos diferenciamos moito dos expósitos da Coruña. Estamos igual de fracos, rapados e moi mal vestidos.

\section{NENO 4}

- Son Antonio Veredia e teño 7 anos. O hospicio de Madrid está desbordado de rapaces, moi por riba dos que debía haber nun espazo daquelas dimensións. Estamos amoreados, mal nutridos e mal vestidos. Poucos de nós sobreviviremos.

\section{NENO 5}

- Son Clemente de la Caridad e teño 9 anos. Fun exposto no torno do hospicio da Coruña e criado en Oleiros. Eu tamén fun escollido para levar a vacina ás Américas. Por suposto, son un expósito, pois ningún pai deixaría emprender semellante viaxe aos seus fillos.

\section{NENO 6}

— Eu son Cándido de la Caridad e teño 7 anos e tamén fun exposto no torno do hospicio da Coruña e criado en San Pedro de Nós. Son forte e san e nunca estiven en contacto coa enfermidade. Por iso tamén formarei parte desta expedición. 


\section{NENO 7}

- Son Francisco Antonio e teño 8 anos. Fun entregado na casa dos Expósitos da Coruña polos mesmos labradores que me levaron para criar; ao cabo de 7 anos fun recuperado pola miña nai, pero só 8 meses, despois volvín ao hospicio. Estou contento de ser un heroe porque aos expósitos sempre nos miraron mal. Considérannos fillos da miseria. O lixo da sociedade.

\section{NENO 8}

— Eu son Manuel María e teño 7 anos. Fun entregado polo párroco de San Nicolás á casa de Expósitos da Coruña e criado en San Pedro de Nós. Alí, hai ben pouco, oín dicir a unha persoa de ben que non mereciamos atención médica, que bastante se facía con sacarnos das rúas. Que mágoa! Esta aventura dará dignidade e sentido ás nosas vidas.

\section{NENO 9}

— Eu son Juan Antonio e teño 6 anos, entregáronme na Inclusa de Santiago. Son de Santa María de Xiá, en Lugo e fun criado en Rivadulla. O outro día contáronme que cando me deixaran no torno, traía unha carta atada á orella dicindo que meus pais volverían por min cando as cousas lles foran mellor, pero xa hai 3 anos diso e aínda sigo aquí.

\section{NENO 10}

- Son Joséf Manuel María e teño 3 anos. Fun exposto no torno da Casa de Expósitos da Coruña e criado en Sada ata os 3 anos. Dentro de 9 ou 10 días vacinaranme xunto co meu compañeiro. $\mathrm{O}$ doutor Balmis di que é necesario levar a vacina in vivo nunha cadea brazo a brazo, con nenos rigorosamente escollidos.

\section{NENO 11}

- Son Josef Jorge Nicolás de los Dolores e teño 2 anos e medio. Fun entregado con 2 anos e a miña crianza continuou no Hospicio da Coruña. Os nenos e nenas expósitos padecemos frecuentemente de tiña, piollos, parasitos, baixo peso e ata deformidades por malos embarazos.

\section{NENO 12}

- Son Pasqual Aniceto e teño 3 anos. Exposto no torno da casa de Expósitos da Coruña e criado en Crendes. Alegreime moito de ser elixido. Tiña compañeiros moi resentidos porque sempre estaban enfermos e non puideron vir con nós, pois é unha travesía perigosa e deberán seguir no hospicio. 


\section{NENO 13}

- Son Jazinto, teño 6 anos. Fun exposto no torno santiagués cunha cintiña azul no puño e criado en Forcarei. Estou triste porque as nenas non poden ir. Tampouco os doentes crónicos, nin os menores de 3 anos. Os expósitos conflitivos deberán tamén quedar.

NENO 14

— Eu son Tomás Melitón e teño 3 anos. Fun exposto no torno da Casa de Expósitos da Coruña e criado en Arteixo. Estou preocupado porque oín dicir que o barco era un feixe de perigos. Haberá accidentes, enfermidades, mareos, pelexas e choros.

\section{NENO 15}

- Son Gerónimo María, teño 6 anos e veño da Inclusa de Santiago e criado en Campo Lameiro . Di o doutor que hai que ter sempre vacina dispoñible en dous nenos, que só teremos algo de febre e algunhas pústulas e que no barco hai hospedaxes separadas para que non contacten os vacinados co resto.

\section{NENO 16}

- Son Martín e teño 5 anos. Fun entregado na Casa de Expósitos da Coruña polo pedáneo de Dorneda, que tamén me recolle para criar durante 3 anos. Contáronnos que durante moito tempo deberemos estar nun recinto moi pequeno e que temos que comportarnos moi ben, sen pelexar, sen correr e sen berrar.

\section{NENO 17}

- Son Juan Francisco, teño 4 anos. Son de Coristanco e fun entregado na Inclusa de Santiago e criado en Abegondo. A reitora Isabel di que os nenos maiores serán titores dos máis pequenos. Durmirán xuntos e velarán polo que fagan e coman.

\section{NENO 18}

— Eu son Joséf e teño 3 anos. Fun exposto no torno do Hospicio da Coruña e criado en Sada. Cando nos vacinen sairannos uns pouquiños grans, que non doen, e deses grans sae a medicina para os outros nenos.

\section{NENO 19}

- Son Florencio, teño 4 anos. Fun exposto no torno da Inclusa de Santiago e criado en Cesuras. Onte vacináronme e era tal a miña ilusión que ata puiden co medo e non dei un chío mentres me facían a incisión coa lanceta no brazo. 


\section{NENO 20}

- Son Vicente María Sale y Vellido, teño 3 anos. Fun exposto no torno do Hospicio da Coruña cun escrito de compromiso de recuperación por parte de meus pais e criado en Arteixo. A min tamén me vacinaron onte, porque hoxe sairá a expedición. Como xa estamos inoculados illáronnos do resto controlándonos cada hora.

NENO 21 e 22

- O meu compañeiro é Ignacio José. Ten 3 anos e foi exposto no torno da casa de Expósitos da Coruña e criado en Sada. Eu son Benito Vélez, teño 7 anos. Son fillo de Isabel Zendal. Ela tamén é a nai de todos os meus compañeiros, é a nosa coidadora e enfermeira. Será imprescindible a súa axuda, rectitude e firmeza para que esta expedición sexa un éxito. Contribuiremos todos ao progreso da ciencia.

\section{Música: “Amo del mesón”.}

\section{ISABEL ZENDAL}

— Son Isabel Zendal. Nacín en Santa Mariña de Parada, unha aldeíña de Ordes, na provincia da Coruña. A miña familia era pobre de solemnidade. Eu traballei moito para converter a Casa de Expósitos nun lugar acolledor e digno. Como sería a miseria nalgunhas casas cando os pais dalgúns rapaces pensaban que neste lugar estarían mellor. Pobres pais e pobres nenos!! Por iso cando o doutor Balmis nos propuxo formar parte desta viaxe nin o dubidamos.

Podedes imaxinar como sería cruzar o océano con vinte e dous nenos a bordo chorando, escapando, pelexando e enfermando? Dixéronnos que os nenos que participasen na expedición terían un futuro asegurado, que non lles faltaría alimento nin roupa na viaxe e que unha vez en América terían unha educación e un oficio. Pero, unha vez rematada a penosa viaxe, as cousas non foron como lles contaran. Balmis reclamou os beneficios que lles prometeran, pero as autoridades locais internáronnos nun hospicio onde vivían mal alimentados e mal coidados. Os máis afortunados foron adoptados por familias mexicanas.

Pero grazas aos expósitos, que saíron da Coruña, conseguimos difundir a vacina en toda América e isto foi un gran logro sanitario. Douscentos anos despois, a varíola xa non existe. En 1980 a Organización Mundial da Saúde declarou o planeta Terra zona cero de varíola. Todo isto foi posible grazas ao labor titánico da Real Expedición Filantrópica da vacina!

Música: "Canta o pobo". 


\section{REFERENCIAS BIBLIOGRÁFICAS}

López Mariño, A. (2018). Isabel Zendal Gómez nos arquivos de Galicia. Galicia: Parlamento de Galicia.

Solar, M. (2017). Os nenos da variola. Galicia: Galaxia.

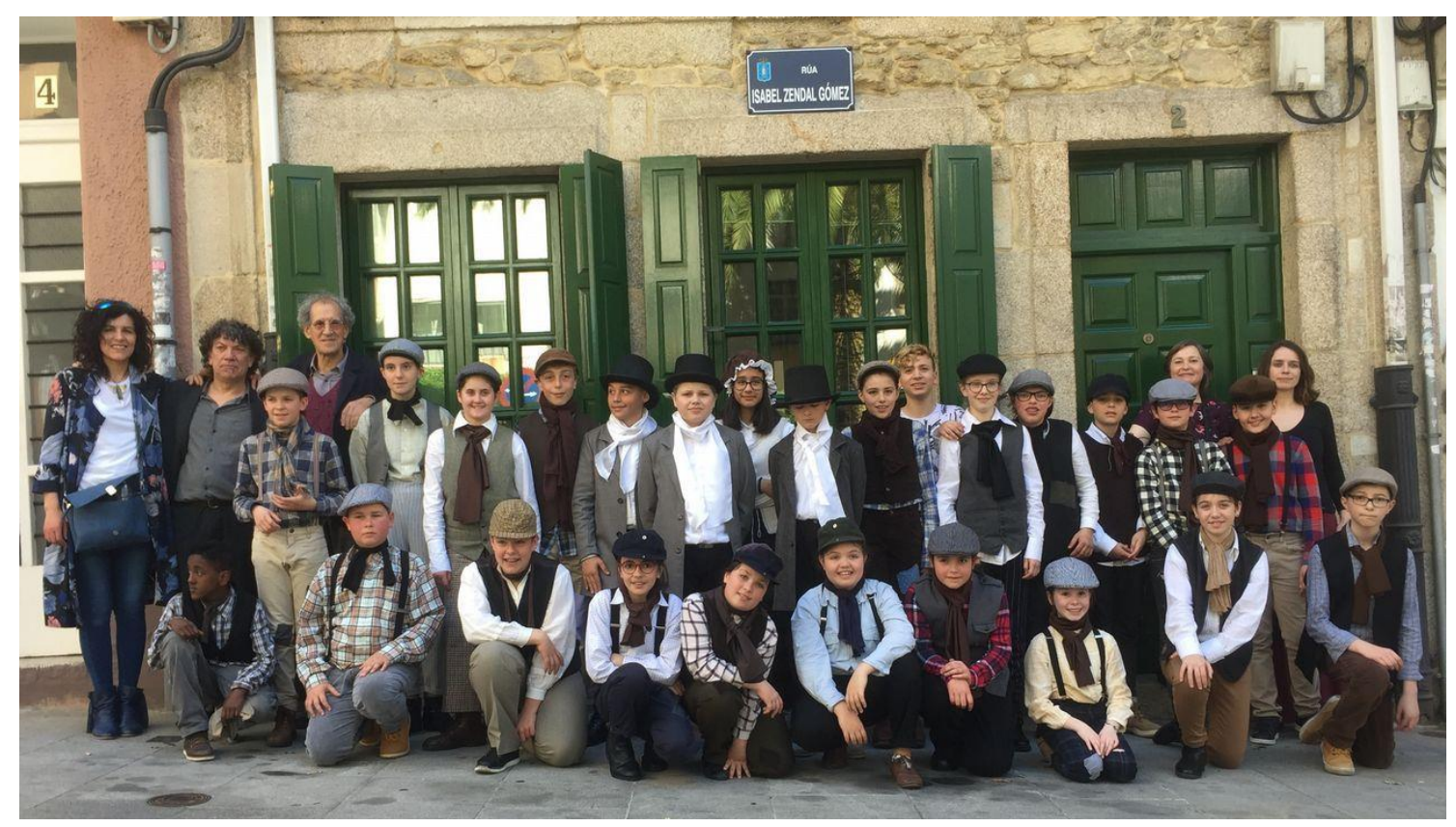

Imaxe de R. García, La Voz de Galicia.

A representación da obra fíxose coincidir co cambio de nome da rúa de Isabel Zendal que aparecía cos apelidos incorrectos 